\title{
Effects of drug solubility, state and loading on controlled release in bicomponent electrospun fibers
}

\author{
Mădălina V. Natu, Hermínio C. de Sousa, M. H. Gil ${ }^{1, *}$ \\ Department of Chemical Engineering, University of Coimbra, Pólo II, Pinhal de \\ Marrocos, 3030-290, Coimbra, Portugal
}

\begin{abstract}
Bicomponent fibers of two semi-crystalline (co)polymers, poly( $\varepsilon$-caprolactone), PCL and poly(oxyethylene-b-oxypropylene-b-oxyethylene), Lu were obtained by electrospinning. Acetazolamide and timolol maleate were loaded in the fibers in different concentrations (below and above the drug solubility limit in polymer) in order to determine the effect of drug solubility in polymer, drug state, drug loading and fiber composition on fiber morphology, drug distribution and release kinetics. The high loadings fibers (with drug in crystalline form) showed higher burst and faster release than low drug content fibers, indicating the release was more sustained when the drug was encapsulated inside the fibers, in amorphous form. Moreover, timolol maleate was released faster than acetazolamide, indicating that drug solubility in polymer influences the partition of drug between polymer and elution medium, while fiber composition also controlled drug release. At low loadings, total release was not achieved (cumulative release percentages smaller than $100 \%$ ), suggesting that drug remained trapped in the fibers. The modeling of release data implied a three stage release mechanism: a dissolution stage, a desorption and subsequent diffusion through water filled pores, followed by polymer degradation control.
\end{abstract}

Keywords: electrospinning, bicomponent fibers, drug release, modeling

\footnotetext{
*Corresponding author

Email address: hgil@eq.uc.pt (M. H. Gil)

${ }^{1}$ tel:+351239798700, fax:+351239798703
} 


\section{Introduction}

Electrospinning is a versatile technique through which a variety of constructs can be obtained with application in biomedicine (medical prosthesis, tissue scaffolds, wound dressings, drug delivery, cosmetics), textiles, electricity and optics, sensors, filtration, catalysis, unconventional energy sources and storage cells $[1,2]$. In the field of drug delivery and tissue engineering, electrospun polymer fibers have gained increasing importance because they present several advantages: relatively easy drug entrapment during the electrospinning process, obtaining of high loadings if so desired, burst control, stability and preservation of drug/growth factor activity, high surface area (which enhances drug release) and specific morphology which can be easily controlled during the electrospining process [3]. Multicomponent fibers have attracted special attention because new properties can be obtained through the combination of different materials. Synthetic polymers with good processability and good mechanical properties can be mixed with natural polymers producing an increase in cellular attachment and biocompatibility [4]. Multicomponent fibers can be obtained mainly by two techniques [5]: direct electrospinning of polymers solution (in a single-needle configuration, if a mixture of polymers is co-dissolved in the electrospinning solution or a multi-needle configuration in which the polymer solutions are separated in parallel or concentric syringes) and post-treatment of the single-component electrospun fibers (which can include coating with other inorganic-polymer layers [6, 7], grafting [8], crosslinking [9], chemical vapour deposition [10], functionalization with other (bio)polymers [11]). In addition to the new physico-chemical properties that arise from using various components, a variety of fiber structures can be obtained such as core-shell fibers, micro/nanotubes, interpenetrating phase morphologies (matrix dispersed or co-continuous fibers) [12, 13], nanoscale morphologies (spheres, rods, micelles, lamellae, vesicle tubules, and cylinders) [14] and multilayered constructs (either with different composition or different fiber diameter) $[15,16]$.

For drug delivery applications, several polymers (in terms of degradability and crystallinity) have been studied as well as drug/growth factor loading in crystalline or amorphous form in order to fulfill specific requirements of drug-eluting fiber mats (usually, good mechanical properties and biocompatibility are required together with control of drug release and burst effect in order to ensure physical integrity of the construct, long term delivery or 
immediate action at the targeted location). There are several factors that can affect the drug release from electrospun fibers: fiber construct geometry and thickness [17], fiber diameter and porosity [18], fiber composition [19], fiber crystallinity [20], fiber swelling [21], drug loading [18, 21], drug state $[22,23]$, drug molecular weight $[19,24]$, drug solubility in the release medium [21], drug-polymer-electrospinning solvent interactions [25, 26]. The release characteristics of the fiber mat are highly influenced by the state of the drug and the structure of the polymer that forms the fiber. For example, the crystallinity of the polymer controls the rate of drug release as semi-crystalline polymers showed in general a higher extent of burst because of two reasons: on one hand, the instantaneous release of the drug deposited at the fiber surface, and on the other hand, the hindered release of the drug from the fiber bulk due to limited water uptake in the semi-crsytalline regions [20]. The drug state in the fibers is also an important factor since it was shown that a drug that is incorporated in crystalline form will mainly be deposited outside the fibers and trigger burst release, while drug in amorphous state will be loaded inside the fibers and be released in a sustained manner [22, 23, 27]. Drug loading is another factor that can affect the drug release: higher loadings will produce faster release $([18,21,22])$; on one hand, at high loadings, there is more surface segregated drug that dissolves fast and on the other hand, there is an increase in porosity during drug elution proportional to the initial amount of drug [18]. Drug compatibility with polymer solution was also shown to be an important factor in controlling release, as lipophilic drugs should be incorporated in lipophilic polymers and hydrophilic drugs in hydrophilic polymers in order to avoid drug deposition outside fibers and subsequent burst [26]. Moreover, the interaction between drug and the polymer can block the crystallization of the drug in the fibers, if so desired [28] and can even determine sustained release of drugs in crystalline state because of chemical interaction with the polymer [24].

In our study, bicomponent fibers were prepared using poly( $\varepsilon$-caprolactone), a semi-crystalline, more hydrophobic polymer and Lutrol F127 (poly(oxyethyleneb-oxypropylene-b-oxyethylene)), also semi-crystalline, hydrophilic block copolymer. Poly( $\varepsilon$-caprolactone) was selected because it has been used in a variety of electrospun fibers applications [3], while Lutrol F127 was added as hydrophilicity enhancer and release modulator [29]. The properties of the bicomponent fibers were studied in order to determine the effect of processing on crystallinity, water contact angle and mass loss. As both polymers are semi-crystalline, we could test the influence of such organization on the 
loading and release of drugs. Two drugs were selected for incorporation in the fibers in different concentrations (below and above the drug solubility limit in polymers), acetazolamide, a hydrophobic drug and timolol maleate, a hydrophilic drug in order to determine the effect of drug solubility in polymer, drug state, drug loading and fiber composition on fiber morphology, drug distribution and release kinetics. Moreover, modeling of the release data using a semi-empirical model (power law [30]) and a mechanistic model (desorption model [31]) was performed, determining the release mechanism, while the models were compared in terms of goodness of fit.

\section{Materials and methods}

\subsection{Materials}

Timolol maleate, (lot no. 90191189, 99,6 \% purity) was purchased from Cambrex Profarmaco Cork Ltd., while acetazolamide was obtained from Sigma-Aldrich. Poly $\left(\varepsilon\right.$-caprolactone) pellets (PCL, average $M_{w} 65000 \mathrm{~g} / \mathrm{mol}$ ) were obtained from Sigma-Aldrich. Lutrol F127 (Lu, 9000-14000 g/mol, $70 \%$ by weight of polyoxyethylene) was bought from BASF. Acetone and methanol, both spectrophotometric grade were obtained from Sigma-Aldrich.

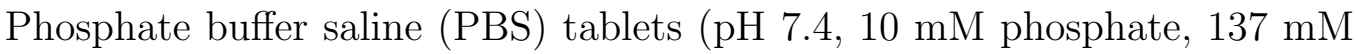
sodium, $2.7 \mathrm{mM}$ potassium), used to prepare the release medium were bought from Sigma-Aldrich. All products were used without further purification.

\subsection{Methods}

\subsubsection{Electrospinning}

Lutrol F127 and PCL mixtures $(25 / 75,50 / 50, \mathrm{w} / \mathrm{w})$ or PCL alone were dissolved in acetone/methanol $(4 / 1, \mathrm{v} / \mathrm{v})$ at $15 \%(\mathrm{w} / \mathrm{v})$ and at $40{ }^{\circ} \mathrm{C}$. The final volume of each polymer solution was $3 \mathrm{ml}$. Acetazolamide and timolol maleate were co-dissolved with the polymers $(1 \%, \mathrm{w} / \mathrm{w})$. The electrospinning set-up consisted of a high voltage power supply (SL 10W-300W, Spellman), delivery system (syringe, teflon tubing, 30 gauge needle, syringe pump (NE-1000 Multiphaser, New Era Pump Systems)) and a rectangular copper collector. A voltage of $20 \mathrm{kV}$ was applied, while the syringe pump was operated at a flow rate of $10 \mathrm{ml} / \mathrm{min}$. Polymeric fibers were deposited on aluminium paper covering the collector placed at a distance of $8 \mathrm{~cm}$ from the needle tip. All electrospinning experiments were carried out under ambient conditions $\left(25^{\circ} \mathrm{C}, 50 \%\right.$ humidity in average). The films deposited on the 
aluminium paper were peeled off and cut in rectangular pieces of $1 \mathrm{~cm} \times 1$ $\mathrm{cm}$. They were used as such in drug release experiments.

\subsubsection{Morphological analysis and drug mapping}

The morphology of the electrospun fiber and drug distribution were examined using scanning electron microscopy (SEM, Jeol JSM 5310) coupled to an X-ray energy dispersion unit to determine the presence of elemental sulphur (present in both drugs). The drug mapping for some of the samples was done using electron probe microanalysis (Camebax SX50, Cameca) at 15 $\mathrm{kV}$ accelerated voltage and $40 \mathrm{nA}$ probe current. SEM images were analyzed using an image analysis software (ImageJ 1.42 [32]) and the average fiber diameter was calculated by measuring the diameter of 40 fibers, selected from different areas of the samples.

\subsubsection{Fiber mat crystallinity, drug solubilitity in polymer and drug state}

Films containing different drug percentages were prepared by solvent casting. Differential scanning calorimetry was carried out on a DSC Q100 equipment (TA Instruments). Samples with masses of approximately $4 \mathrm{mg}$ were heated until $350{ }^{\circ} \mathrm{C}$, at a heating rate of $10{ }^{\circ} \mathrm{C} / \mathrm{min}$ in a hermetic pan, under nitrogen atmosphere $(100 \mathrm{~mL} / \mathrm{min})$. Drug concentration in the film was plotted against drug melting enthalpy (calculated using Universal Analysis 2000 software (TA Instruments)) and the drug solubility in the polymer (as percentage) was determined as the intercept of the linear regression curve. The relative crystallinity of the fibers was calculated using Eq. 1.

$$
\mathrm{X}_{\mathrm{rel}}(\%)=\frac{\Delta \mathrm{H}_{\mathrm{f}}}{\mathrm{x}_{\mathrm{Lu}} \Delta \mathrm{H}_{\mathrm{f}, 100 \% \mathrm{Lu}}+\mathrm{x}_{\mathrm{PCL}} \Delta \mathrm{H}_{\mathrm{f}, 100 \% \mathrm{PCL}}} \times 100
$$

where $\Delta H_{f}$ is the melting enthalpy determined in analysis by integrating the peaks corresponding to polymer/blend melting, $\mathrm{x}_{L u}$ and $\mathrm{x}_{P C L}$ are $\mathrm{Lu}$ and PCL mass fractions in the blend, while $\Delta H_{f, 100 \% L u}=181 \mathrm{~J} / \mathrm{g}$ is the melting enthalpy of $100 \%$ crystalline $\mathrm{Lu}$ and $\Delta H_{f, 100 \% P C L}=142 \mathrm{~J} / \mathrm{g}$ is the melting enthalpy of $100 \%$ crystalline PCL [33]. The melting enthalpy of $100 \%$ crystalline Lu was calculated using Eq. 2.

$$
\Delta \mathrm{H}_{\mathrm{f}, 100 \% \mathrm{Lu}}=\mathrm{x}_{\mathrm{PPO}} \Delta \mathrm{H}_{\mathrm{f}, 100 \% \mathrm{PPO}}+\mathrm{x}_{\mathrm{PEO}} \Delta \mathrm{H}_{\mathrm{f}, 100 \% \mathrm{PEO}}
$$

where $\mathrm{x}_{P P O}$ and $\mathrm{x}_{P E O}$ are polypropyleneoxide and polyethyleneoxide mass fractions in Lutrol and $\Delta H_{f, 100 \% P P O}$ and $\Delta H_{f, 100 \% P E O}$ are the corresponding melting enthalpies of $100 \%$ crystalline polymer [34]. 


\subsubsection{Swelling and mass loss}

Fiber films were accurately weighed and immersed in $4 \mathrm{ml}$ phosphate saline buffer (PBS) in sealed vials at $37^{\circ} \mathrm{C}$. At scheduled time intervals, samples were withdrawn from the vials, blotted with a tissue paper to remove the surface water and weighed. The water content $(\Delta \mathrm{w})$ was calculated using the Eq. 3.

$$
\Delta \mathrm{w}(\%)=\frac{\mathrm{m}_{\mathrm{t}}-\mathrm{m}_{\mathrm{i}}}{\mathrm{m}_{\mathrm{t}}} \times 100
$$

where $\mathrm{m}_{t}$ denotes the mass of the wet sample at immersion time $\mathrm{t}$ and $\mathrm{m}_{i}$ denotes the initial mass of the sample.

For mass loss determination, at scheduled time intervals, samples were withdrawn from the vials and vacuum dried until constant weight at $37^{\circ} \mathrm{C}$. The percentage of mass loss $(\Delta \mathrm{m})$ was calculated using Eq. 4.

$$
\Delta \mathrm{m}(\%)=\frac{\mathrm{m}_{\mathrm{i}}-\mathrm{m}_{\mathrm{d}}}{\mathrm{m}_{\mathrm{i}}} \times 100
$$

where $\mathrm{m}_{i}$ denotes the initial mass and $\mathrm{m}_{d}$ is the mass of the dried sample after a certain immersion time.

\subsubsection{Drug loading and release}

The drug release from the fibers was studied in PBS medium $(4 \mathrm{ml})$, using a shaker $\left(37^{\circ} \mathrm{C}, 100 \mathrm{rpm}\right)$. At scheduled time intervals $(1,2,3,4,7$, $8,9,10,11,15,19,36,52$ days), $2 \mathrm{ml}$ of sample was taken and fresh PBS medium of identical volume was added to maintain sink conditions. The mass of timolol maleate and acetazolamide released at time t, $m_{t}$, as well as the total drug amount $\left(m_{\text {tot }}\right)$ were determined by UV spectroscopy (Jasco V-650 Spectrophotometer) at $299.5 \mathrm{~nm}$ and $265 \mathrm{~nm}$, in PBS and 4/1 (v/v) $\mathrm{THF} /$ methanol solution, respectively. The drug loading was determined using Eq. 5. The percentage of released drug was calculated using Eq. 6. Calculations of the amount of released drug took into account replacement with fresh medium at each sampling point. Controls (fibers without drug) were also tested and their contribution to the absorbance was substracted.

$$
\text { Loading }(\%)=\frac{\mathrm{m}_{\text {tot }}}{\mathrm{m}_{\text {fiber }}} \times 100
$$

in which $m_{\text {fiber }}$ is the mass of the fiber mat.

$$
\text { Released } \operatorname{drug}(\%)=\frac{\mathrm{m}_{\mathrm{t}}}{\mathrm{m}_{\mathrm{tot}}} \times 100
$$


In order to study the drug release mechanism, different equations (Eq.7, 8 ) were used to model the release data. The equations were fitted to the data using non-linear regression and the results were compared in terms of goodness of the fit. The power law equation (Eq.7) is one of them and was chosen because it is the most widely used equation in works concerning drug release [30]:

$$
\frac{\mathrm{m}_{\mathrm{t}}}{\mathrm{m}_{\mathrm{tot}}}=\mathrm{a}_{0}+\mathrm{kt}^{\mathrm{n}}
$$

where $m_{t} / m_{t o t}$ is the fractional release of the drug at time $t, a_{0}$ is a constant, representing the percentage of burst release, $k$ is the kinetic constant and $n$ is the release exponent, indicating the mechanism of drug release.

In most models, the release mechanism has been attributed to diffusion of the drug from the polymers and under this assumption, a $100 \%$ release of the drug is expected in a certain time. In the desorption model, the authors suggest that release is not controlled by solid-state diffusion, but by the desorption of the drug from pores of the fibers or from the outer surface of the fibers. Thus, only the drug on the fiber and pore surfaces can be released, whereas the drug from the bulk can not be released within the time scales characteristic of the release experiments. The Eq.8 is based on a pore model, in which the effective drug diffusion coefficient, $D_{\text {eff }}$ is considered and not the actual diffusion coefficient in water, $D$ (with $D_{\text {eff }} / D \ll 1$ ) because desorption from the pore is the rate limiting step and not drug diffusion in water, which is relatively fast.

$$
\frac{\mathrm{m}_{\mathrm{t}}}{\mathrm{m}_{\mathrm{tot}}}=\alpha\left[1-\exp \left(-\frac{\pi^{2}}{8} \frac{\mathrm{t}}{\tau_{\mathrm{r}}}\right)\right]
$$

where the porosity factor $\alpha=m_{s 0} /\left(m_{s 0}+m_{b 0}\right)<1$, with $\mathrm{m}_{s 0}$ and $\mathrm{m}_{b 0}$ being the initial amount of drug at the fiber surface and the initial amount of drug in the fiber bulk, respectively; $m_{t}$ is the drug amount released at time $t$, while the total initial amount of drug in the fiber is $m_{t o t}=m_{s 0}+m_{b 0}$ and $\tau_{r}$ is the characteristic time of the release process[31].

\subsubsection{Statistics}

All values are presented as mean $(n=3)$ and standard error of the mean (SEM). Linear regression analysis was performed using OpenOffice.org Calc 3.1 [35], while non-linear regression was done using the regression module of SigmaPlot 10 [36]. Adjusted $R^{2}\left(A d j R^{2}\right)$ was calculated instead of $R^{2}$ to 


\begin{tabular}{ccccc}
\hline Sample & \multicolumn{2}{c}{ Drug solubility (\%) } & \multicolumn{2}{c}{ Rel. degree of crystallinity (\%) } \\
& Timolol maleate & Acetazolamide & Timolol maleate & Acetazolamide \\
\hline PCL & $4.48(1.11)$ & $16.53(2.1)$ & 54.39 & 54.59 \\
$25 / 75 \mathrm{Lu} /$ PCL & $5.14(0.94)$ & $15.94(4.81)$ & 54.71 & 59.55 \\
$50 / 50 \mathrm{Lu} /$ PCL & $6.97(1.86)$ & $14.81(0.8)$ & 64.01 & 59.89 \\
$\mathrm{Lu}$ & $8.34(1.54)$ & $11.25(3.92)$ & & \\
\hline
\end{tabular}

Table 1: Drug solubility in polymer

evaluate goodness of fit for the two equations that have different number of model parameters.

\section{Results and discussion}

\subsection{Fiber mat crystallinity, drug solubilitity in polymer and drug state}

In this work, two drugs, timolol maleate $\left(\mathrm{pk}_{a}=3.9\right.$, experimental $\log \mathrm{P}=$ 1.2 , experimental water solubility $=2.74 \mathrm{mg} / \mathrm{ml}[37])$ and acetazolamide $\left(\mathrm{pk}_{a}=7.2\right.$, experimental $\log \mathrm{P}=-0.26$, experimental water solubility $=0.98 \mathrm{mg} / \mathrm{ml}[38]$ ) with the chemical structures shown in Fig. 1 were chosen because of different hydrophilic/hydrophobic character that would allow us to understand how the interactions between the drug and polymers contribute to drug release. Thus, as a measure of interaction, the drug solubility in polymers was determined and the obtained results are presented in Table 1. Moreover, the drug solubility is expected to influence the loading and the state of the drug in the fibers. Thus, fibers with low and high drug loadings (see Table 4) were prepared corresponding to drug percentages below and above the drug solubility limit, respectively.

It was observed that acetazolamide had higher solubility in all fibers when compared to timolol maleate probably because of enhanced interaction with the hydroxyl/carboxyl groups of the polymers (the chemical structures are shown in Fig.1). Furthermore, a tendency of increase in solubility was noticed when PCL ratio is increased. On the other hand, timolol is more hydrophilic, therefore a higher solubility is expected in the fibers that contain more Lu and are more hydrophilic, which is the case of 50/50 Lu/PCL [29]. An opposite trend was observed for timolol maleate when an increase in solubility was obtained with decrease in PCL content. We will discuss in section 3.4 how the solubility affects the drug release. 


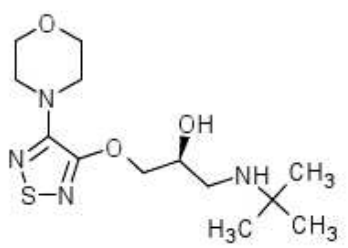

Acetazolamide

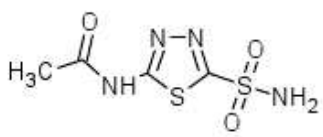

Timolol

$$
\left.\mathrm{H} O \mathrm{II}_{\mathrm{O}}^{\mathrm{C}}-\left(\mathrm{CH}_{2}\right)_{5}-\mathrm{O}\right]_{\mathrm{n}}^{\mathrm{H}}
$$

Poly( $\varepsilon$-caprolactone)

$$
\left.\left.\left.\mathrm{HO}-\left[\mathrm{CH}_{2}-\mathrm{CH}_{2}-\mathrm{O}-\right]_{\mathrm{x}}^{\mathrm{C}} \mathrm{CH}-\mathrm{CH}_{2}-0\right]\right]_{\mathrm{y}}^{\mathrm{CH}_{3}} \mathrm{CH}_{2}-\mathrm{CH}_{2}-0\right]_{\mathrm{x}}^{\mathrm{H}}
$$

Lutrol F 127

Figure 1: Chemical structures 
Polymer crystallinity is known to play an important role in determining degradability, water and drug release because the bulk crystalline phases are more inaccessible to water. The polymers used in this work are semicrystalline and the obtained fibers are expected to be semi-crystalline too. DSC analysis confirmed this hypothesis showing a clear melting peak in all fibers (PCL melts at $65.1{ }^{\circ} \mathrm{C}$ and Lu melts at $59.4{ }^{\circ} \mathrm{C}$ ). The relative degree of crystallinity of drug loaded fibers is presented in Table 1 , where it can be seen that the fibers showed similar crystallinity values regardless the type of loaded drug. Another important fact was that the drug appeared to be in amorphous state in fibers with low drug loadings as proven by the absence of drug melting peak in Fig. 2 (acetazolamide melts at $271.0^{\circ} \mathrm{C}$, while timolol maleate melts at $205.6{ }^{\circ} \mathrm{C}$ ). In fibers with high loadings, part of the drug was in crystalline form as confirmed by morphological analysis (in the DSC scans of these sample (Fig. 3), there is a broad peak possibly corresponding to drug melting, that is unfortunately masked by fiber degradation process that starts at around $250{ }^{\circ} \mathrm{C}$ ).

\subsection{Morphological analysis and drug mapping}

The morphology of the fibers with low drug loadings as function of composition is presented in Fig. 4, while the calculated fiber diameters are shown in Table 2. There was a slight variation in fiber diameter as a function of loaded drug and a more significant one with respect to fiber composition. Morphological differences between samples loaded with the two drugs above or below the solubility limit were also assesed by SEM analysis. In Fig.5(a) and Fig. 5(c) surface and cross-section images of fibers that contain acetazolamide above solubility limit are shown. As the loaded mass of drug was above the solubility limit in the polymer, the drug was expected to be in crystalline form as confirmed by the images where drug crystals were visible outside or inside the fibers. On the other hand, no crystals were observed in the fibers that contain drug in low loadings (Fig.4) suggesting that the drug was in amorphous state in the fibers in agreement with DSC analysis results.

SEM coupled with elemental analysis was performed in order to assess the drug distribution inside the fiber mats. It was seen that both surface and cross-section showed relatively homogeneous drug distribution regardless of composition or type of loaded drug (Fig. 5(b) to Fig. 6(d)). 


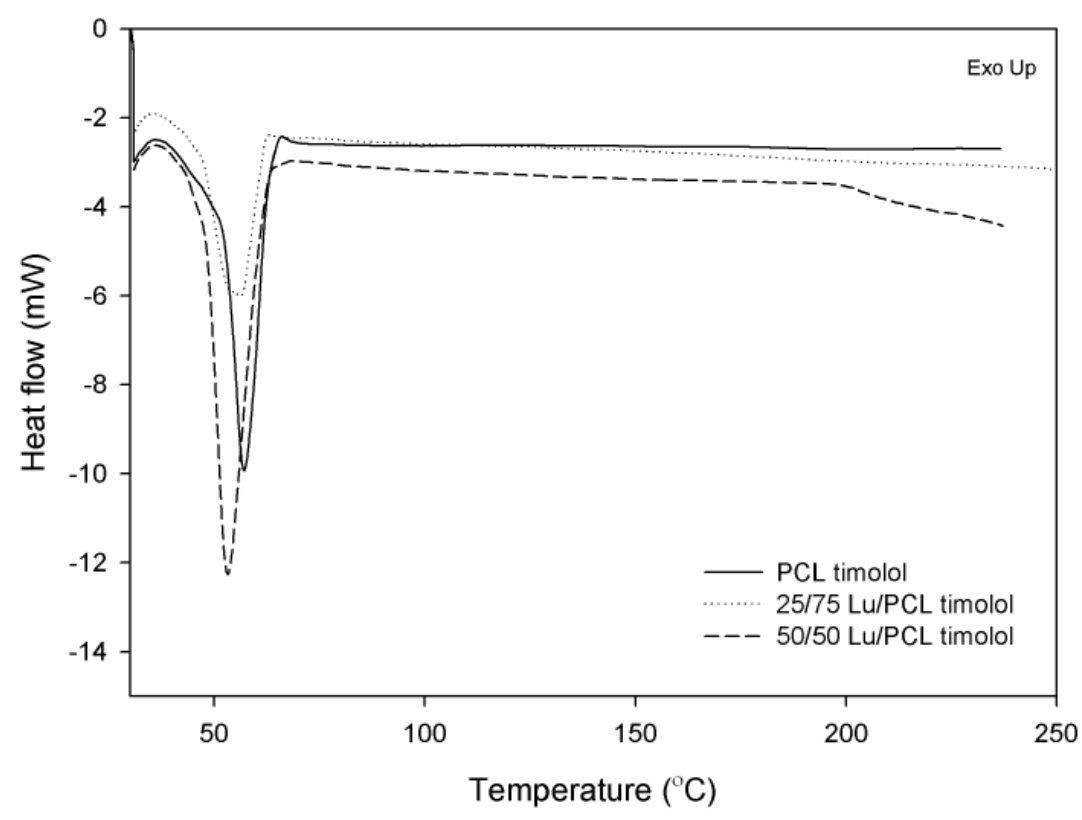

(a)

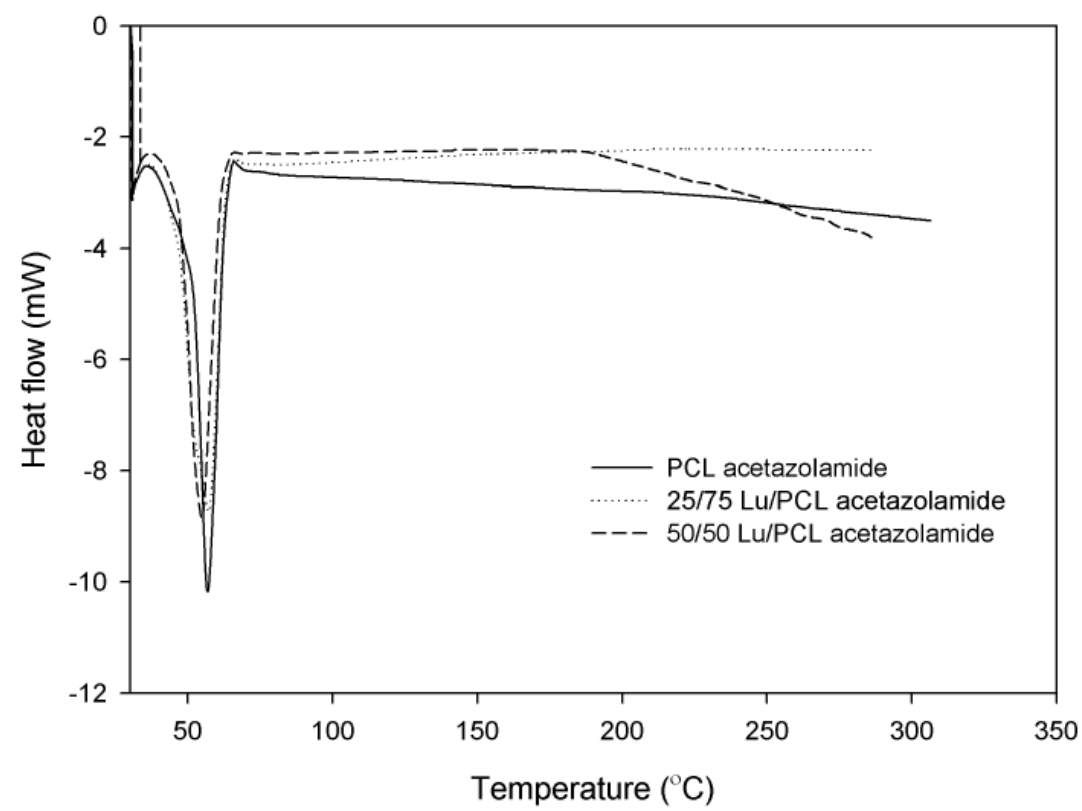

(b)

Figure 2: DSC curves of fiber mats. a) low timolol loading; b) low acetazolamide loading 


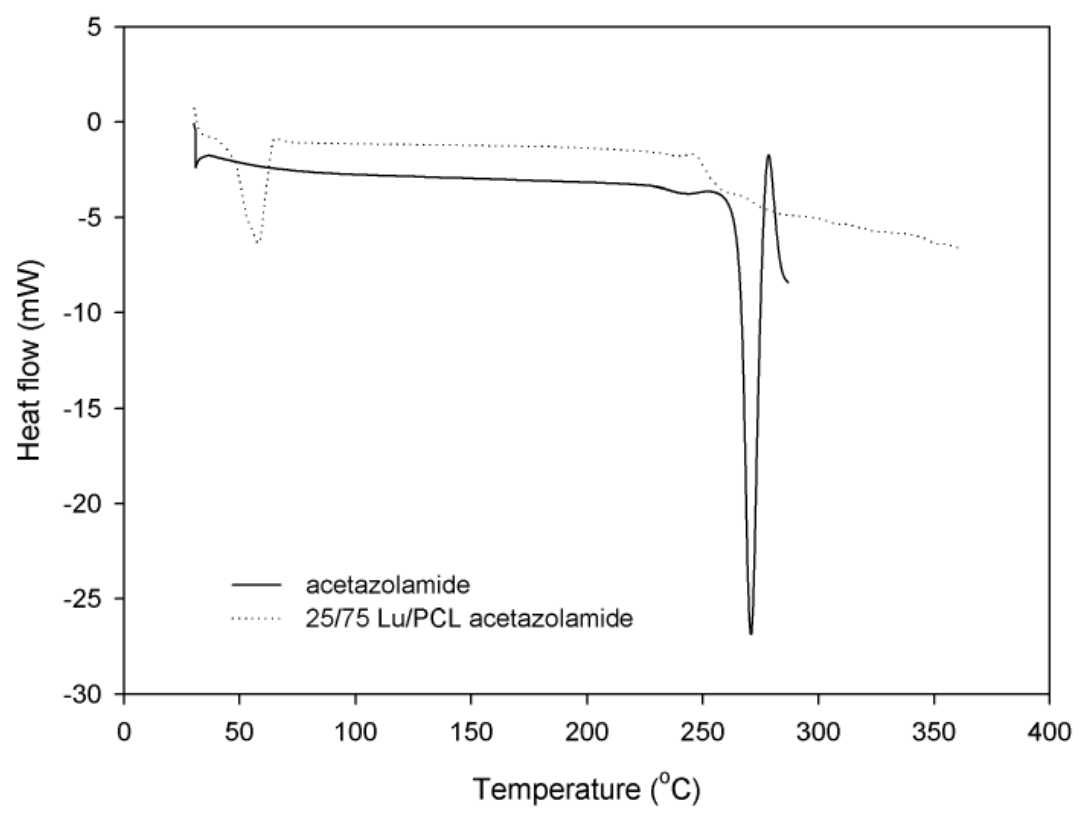

Figure 3: DSC curves of fiber mats with high acetazolamide loading versus pure drug

\begin{tabular}{ccc}
\hline sample & drug & $\mathrm{d}(\mu \mathrm{m})$ \\
\hline PCL & timolol & $1.59(0.36)$ \\
PCL & acetazolamide & $0.71(0.45)$ \\
$25 / 75 \mathrm{Lu} / \mathrm{PCL}$ & timolol & $1.01(0.20)$ \\
$25 / 75 \mathrm{Lu} / \mathrm{PCL}$ & acetazolamide & $0.87(0.45)$ \\
$50 / 50 \mathrm{Lu} / \mathrm{PCL}$ & timolol & $0.56(0.11)$ \\
$50 / 50 \mathrm{Lu} / \mathrm{PCL}$ & acetazolamide & $0.55(0.12)$ \\
\hline
\end{tabular}

Table 2: Fiber diameters 


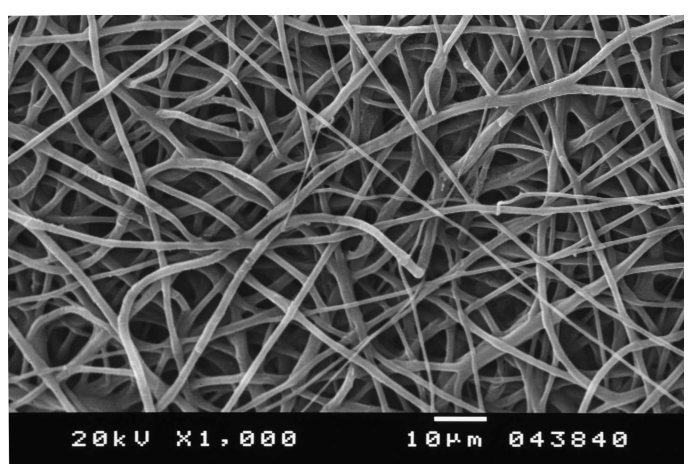

(a)

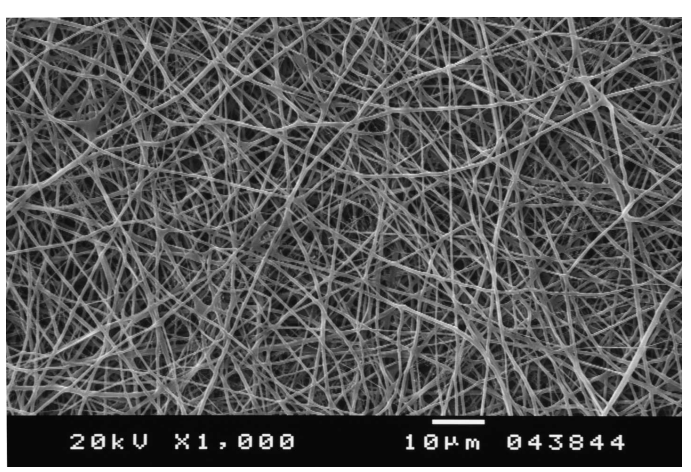

(b)

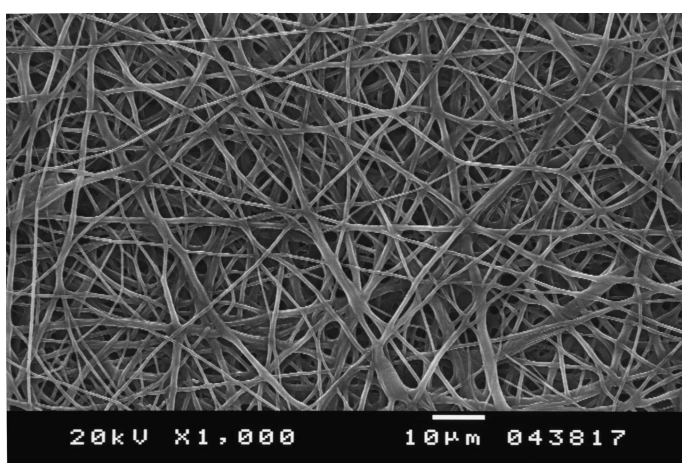

(c)

Figure 4: SEM images of fibers with low drug loadings. a) PCL with timolol; b) 50/50 $\mathrm{Lu} / \mathrm{PCL}$ with timolol; c) $25 / 75 \mathrm{Lu} / \mathrm{PCL}$ with acetazolamide 


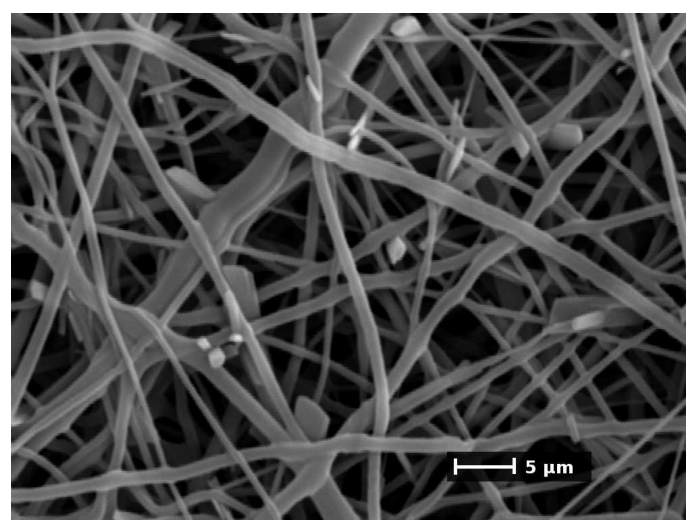

(a)

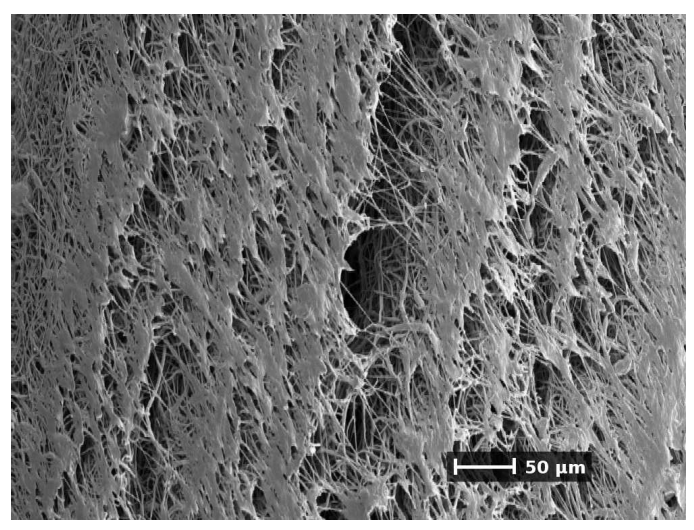

(c)

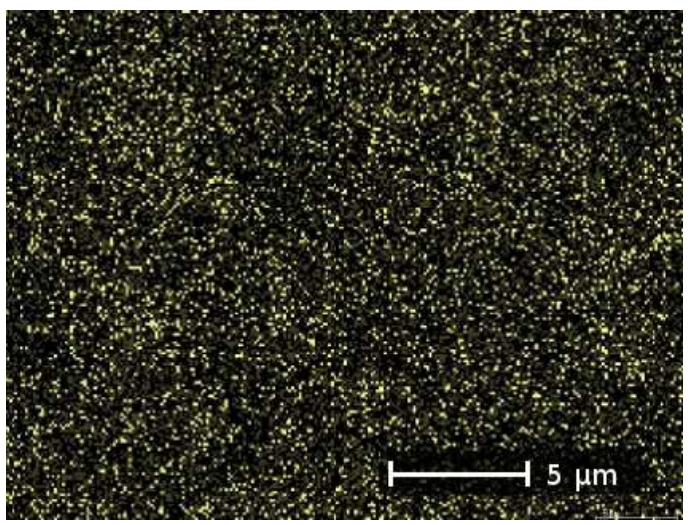

(b)

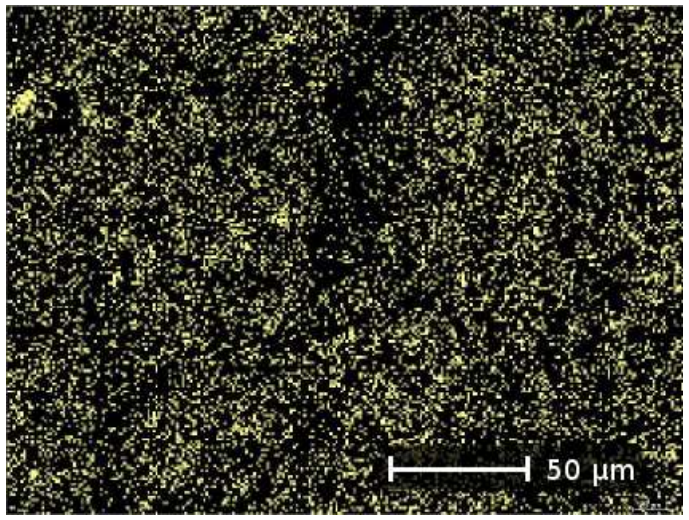

(d)

Figure 5: SEM of high acetazolamide content 25/75 Lu/PCL fibers and sulphur mapping. a) Surface view; b) Surface mapping; c) Cross-section view; d) Cross-section mapping 


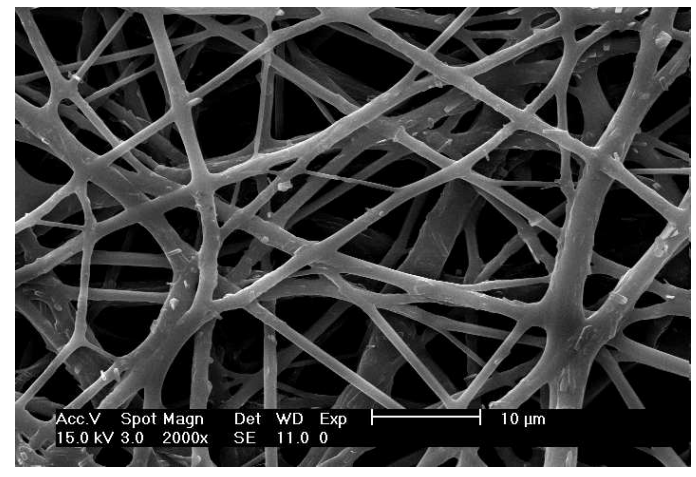

(a)

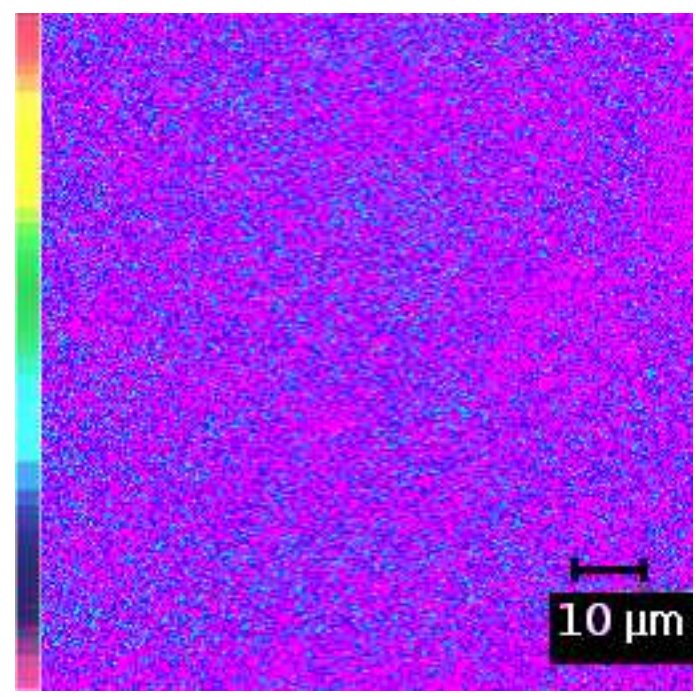

(c)

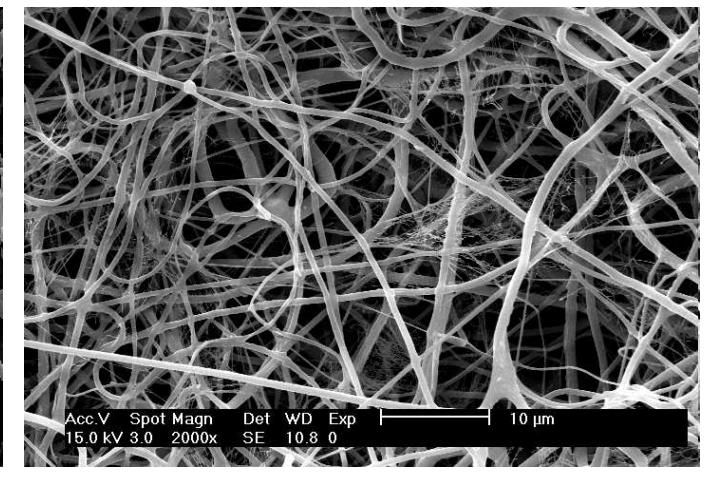

(b)

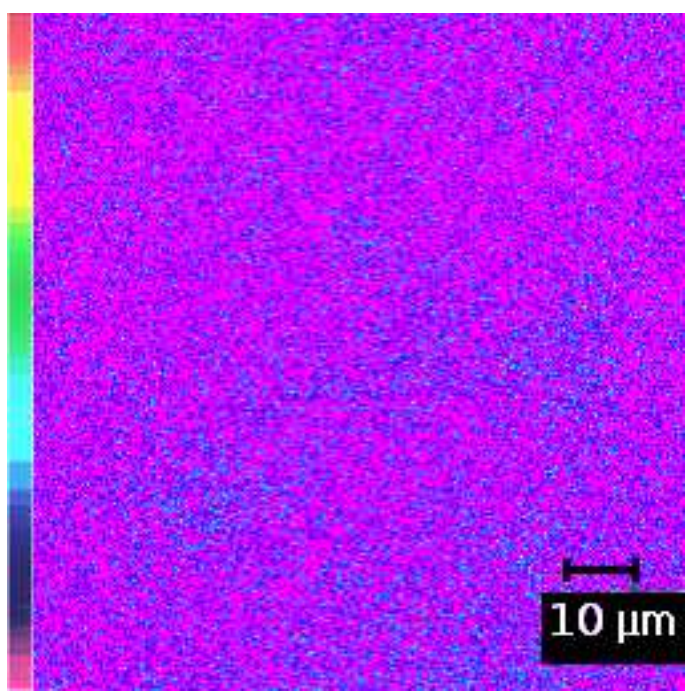

(d)

Figure 6: SEM of high timolol content fibers and sulphur mapping. a) PCL, surface view; b) 25/75 Lu/PCL, surface view; c) PCL, surface mapping; d) 25/75 Lu/PCL, surface mapping 


\begin{tabular}{cc}
\hline sample & contact angle \\
\hline PCL & $123.18(0.98)$ \\
$25 / 75 \mathrm{Lu} / \mathrm{PCL}$ & $18.28(4.07)$ \\
$50 / 50 \mathrm{Lu} / \mathrm{PCL}$ & $16.25(2.16)$ \\
\hline
\end{tabular}

Table 3: Static contact angle with water

\subsection{Swelling and mass loss}

The fiber mats are supposed to function in an aqueous environment, so their properties in the presence of water have to be known. In Table 3, the values of the water contact angles are given for the different fibers. PCL fibers were highly hydrophobic, while the bicomponent fibers were highly hydrophilic. These results were surprising since in a previous work films with the same compositions presented contact angles in the range 50-62 degrees [29]. Water contact angle is determined by both chemical structure and surface morphology. In general, fiber mats have a rougher surface morphology when compared to films and as a result they present higher contact angle than the films made of the same polymers [39]. It seems this is the case of PCL that showed an increase in water contact angle from 62 for films to 123 for fibers. In contrast, the bicomponent fibers presented much lower contact angles probably because of a preferential arrangement of Lu (that is very hydrophilic) towards the margin of the fibers. Lu has a lower molecular weight than PCL and higher molecular mobility and consequently it migrates to the regions of highest shear rate (at the walls of the needle). The higher viscosity component (PCL) occupies mostly the center of the fiber [40].

Consequently, PCL fibers absorbed water gradually (see Fig. 7(a)) because the fibers were hydrophobic and semi-crystalline, hindering the water penetration inside the fiber mat, while the bicomponent fibers presented a sudden increase in water content during the first day $(79.0 \%$ for $50 / 50$ $\mathrm{Lu} / \mathrm{PCL}$ and $68.5 \%$ for $25 / 75 \mathrm{Lu} / \mathrm{PCL})$, followed by a constant value thereafter as $\mathrm{Lu}$ content in the fiber was diminished due to dissolution.

As observed in the mass loss plot (Fig.7(b)), there was an initial increase in mass loss for bicomponent fibers $(42.5 \%$ for $50 / 50 \mathrm{Lu} / \mathrm{PCL}$ and $16.6 \%$ for $25 / 75 \mathrm{Lu} / \mathrm{PCL}$ ), while PCL fibers did not show almost any mass loss $(0.45 \%)$. Mass loss of PCL is detectable only after the molecular weight reaches a value of $10000 \mathrm{~g} / \mathrm{mol}$ [41] and thus the initial high mass loss of the 
bicomponent fibers can only be attributed to the dissolution of $\mathrm{Lu}$ as the sample with higher Lu content had the highest mass loss.

The morphology of aged fibers (immersed in PBS during 3 days) was also investigated in order to determine the change in fiber structure. In Fig.8(a), it can be noticed the smooth surface of the fibers, while in Fig.8(b) pores were observed that were formed due to the dissolution and leaching of $\mathrm{Lu}$. A different appearance was shown by $25 / 75 \mathrm{Lu} / \mathrm{PCL}$ fiber mat (Fig.8(d)), where the fibers appeared more wrinkled in comparison with the initial ones and no pores were visible, probably because of lower Lu content.

\subsection{Drug release}

We previously showed how the fiber morphology and drug deposition were affected by the drug state in the fibers: when drug was in amorphous state, it was incorporated inside the fibers, while the drug present in amounts above the solubility limit crystallized inside and on the fiber surface (as shown in Fig. 5(a)). In Fig. 9(a) and Fig. 9(b), the cumulative percentage of released acetazolamide and timolol maleate from fibers with low drug content is presented, while in Fig. 10(a), the released drug for fibers with high loadings is shown. It was noticed that fibers with high drug loading presented burst release in contrast with low drug content fibers that showed a more sustained release. The former contained drug crystals at the fiber surface or inside the fibers that were not totally encapsulated and were instantaneously "released", implying that the predominant mechanism of release was drug dissolution. On the other hand, in the low loadings fibers, the drug was amorphous and dissolved in the fiber, decreasing burst. These findings were in agreement with another study where bicomponent fibers loaded with $25 \%$ drug (by weight) showed burst release as opposed to $5 \%$ drug fibers [20] that did not, suggesting that the drug state can control the burst extent.

In Table 4, the results of non-linear regression are presented. The objective behind fitting these equations to the release data was to understand the underlying phenomena involved in the drug release mechanism. The parameters $a_{0}, \alpha$ and $k$ define the burst stage and the bigger values they have, the higher extent of burst. On the other hand, $\tau$ and $n$ indicate the magnitude of the drug desorption/diffusion stage and the higher values they have, more sustained is the release.

Drug solubility in polymer as well as drug solubility in solution are important as they control the partitioning of the drug from the polymer toward 


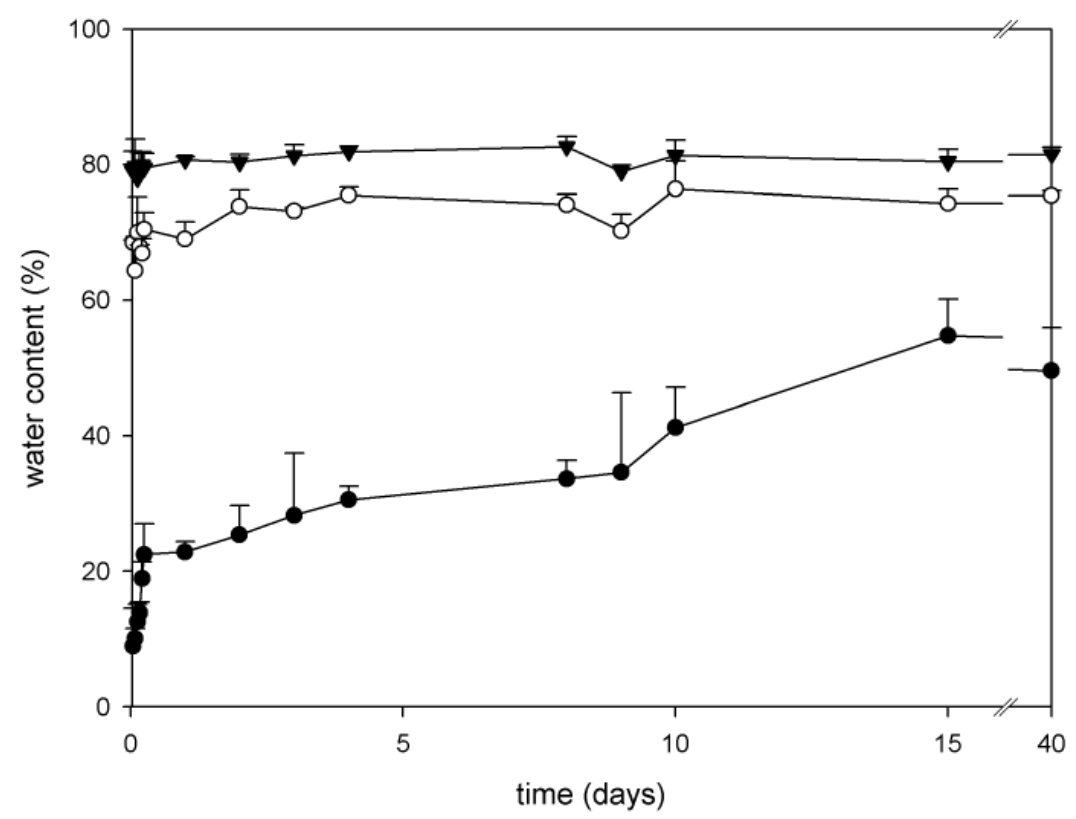

(a)

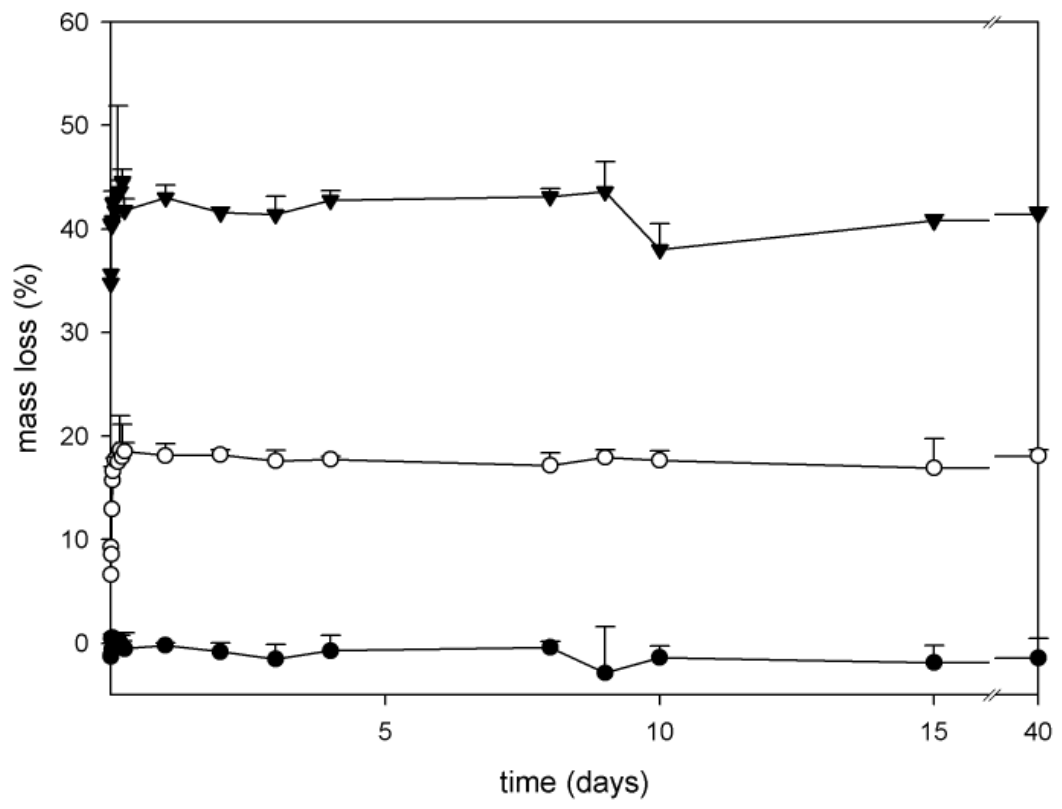

(b)

Figure 7: Water uptake and mass loss, (•) PCL, (०) 25/75 Lu/PCL, ( $)$ 50/50 Lu/PCL 


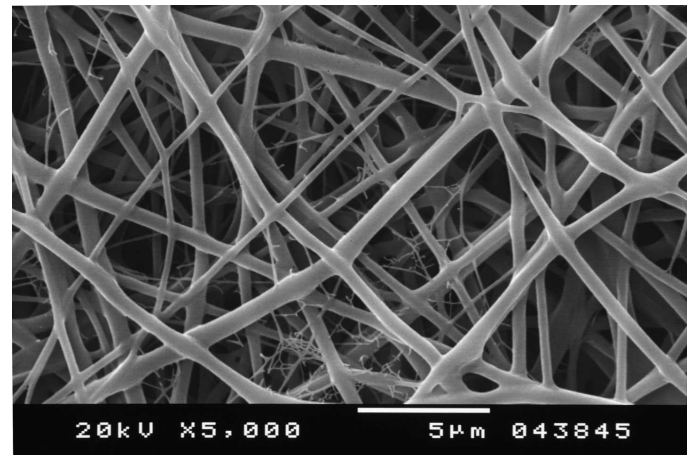

(a)

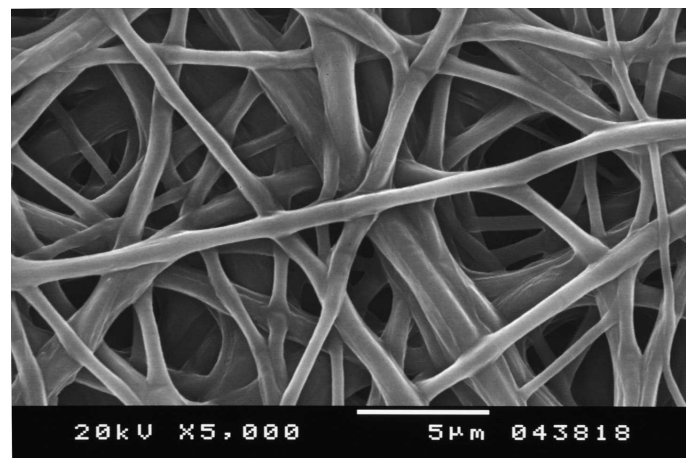

(c)

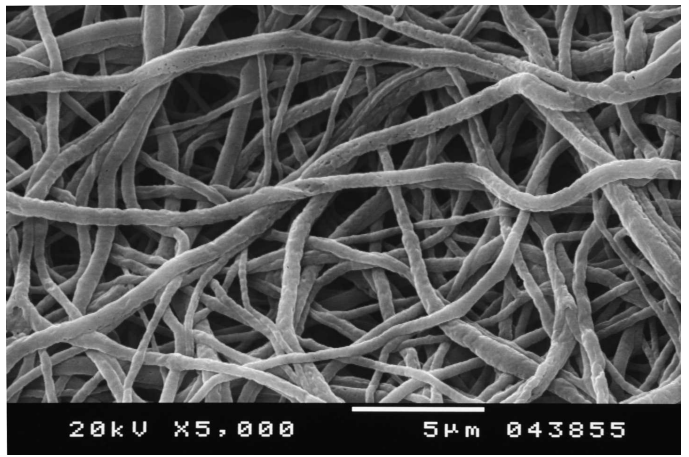

(b)

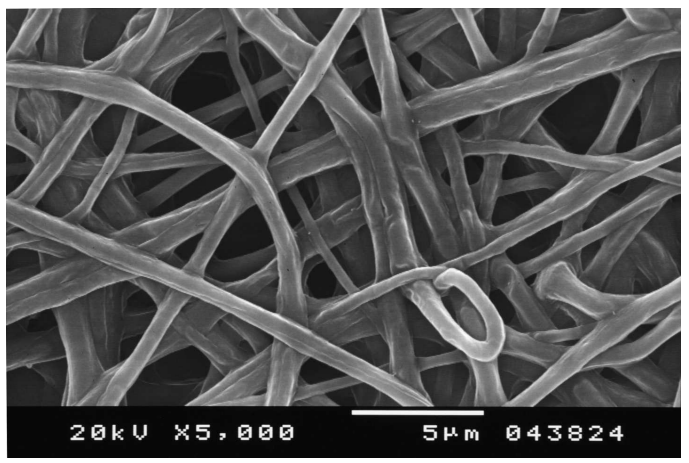

(d)

Figure 8: SEM images of a) initial 50/50 Lu/PCL, b) 50/50 Lu/PCL aged, c) initial 25/75 $\mathrm{Lu} / \mathrm{PCL}, \mathrm{d}) 25 / 75 \mathrm{Lu} / \mathrm{PCL}$ aged 


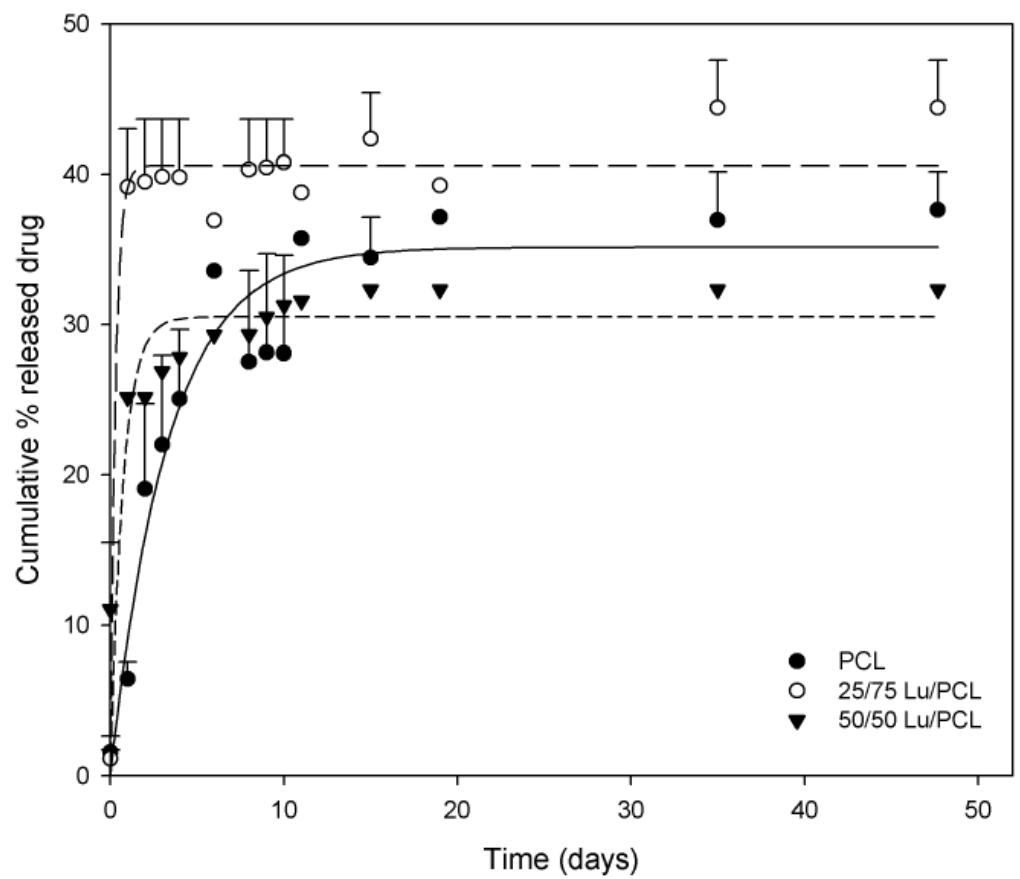

(a)

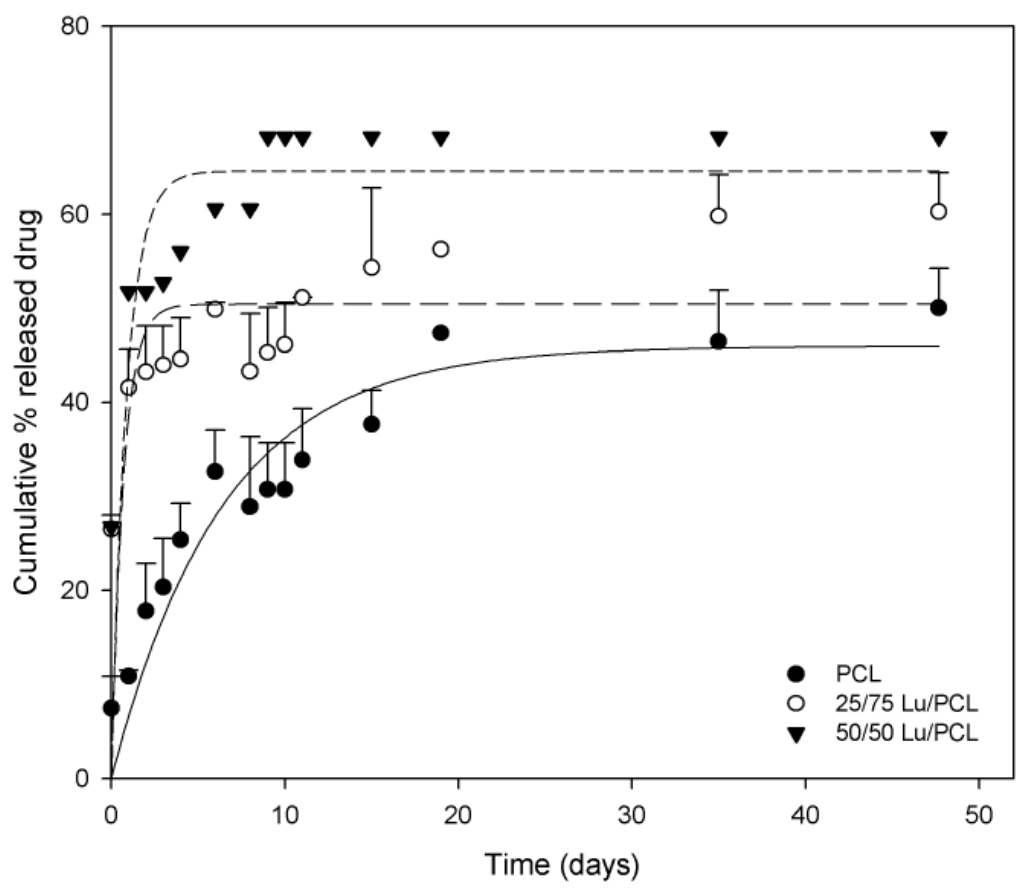

20

(b)

Figure 9: Drug release a) low loadings fibers with acetazolamide, b) low loadings fibers with timolol maleate (solid and dashed lines corresponding to non-linear fit of Eq.8) 


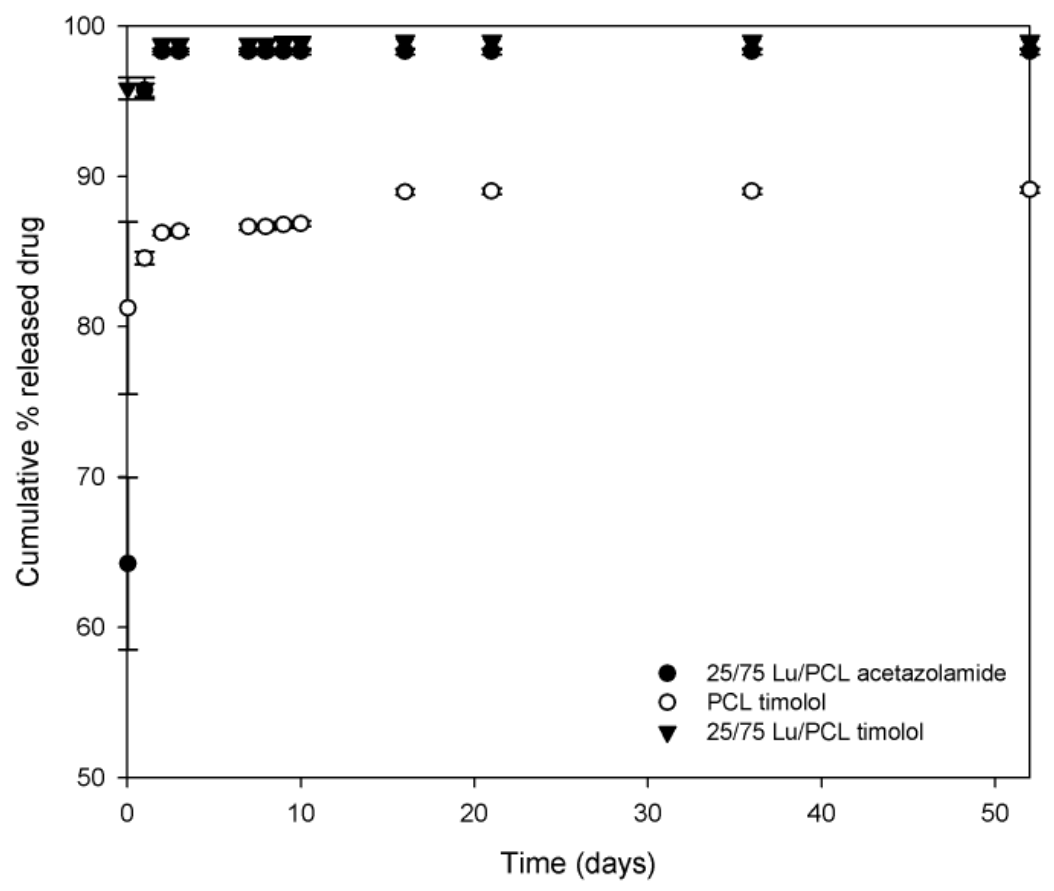

(a)

Figure 10: Drug release of high loadings fibers 


\begin{tabular}{|c|c|c|c|c|c|c|c|c|}
\hline \multirow[t]{2}{*}{ Sample } & \multirow{2}{*}{$\begin{array}{l}\text { Loading } \\
(\%, \\
\mathrm{w} / \mathrm{w})\end{array}$} & \multicolumn{3}{|c|}{ Desorption model } & \multicolumn{4}{|c|}{ Power law } \\
\hline & & $\alpha$ & $\tau$ (days) & Adj $R^{2}$ & $a_{0}$ & $\begin{array}{l}\mathrm{k} \\
\left(\text { day }^{-n}\right)\end{array}$ & $\mathrm{n}$ & Adj $R^{2}$ \\
\hline $\begin{array}{l}\text { PCL, } \\
\text { timolol }\end{array}$ & $\begin{array}{l}0.88 \\
(0.01)\end{array}$ & $\begin{array}{l}45.96 \\
(2.92)\end{array}$ & $\begin{array}{l}7.94 \\
(0.03)\end{array}$ & 0.86 & $\begin{array}{l}5.08 \\
(3.63)\end{array}$ & $\begin{array}{l}11.51 \\
(3.23)\end{array}$ & $\begin{array}{l}0.37 \\
(0.06)\end{array}$ & 0.92 \\
\hline $\begin{array}{l}25 / 75 \\
\mathrm{Lu} / \mathrm{PCL}, \\
\text { timolol }\end{array}$ & $\begin{array}{l}0.86 \\
(0.02)\end{array}$ & $\begin{array}{l}50.41 \\
(2.95)\end{array}$ & $\begin{array}{l}0.87 \\
(0.76)\end{array}$ & 0.00 & $\begin{array}{l}26.93 \\
(2.71)\end{array}$ & $\begin{array}{l}12.58 \\
(2.72)\end{array}$ & $\begin{array}{l}0.26 \\
(0.05)\end{array}$ & 0.90 \\
\hline $\begin{array}{l}50 / 50 \\
\mathrm{Lu} / \mathrm{PCL}, \\
\text { timolol }\end{array}$ & $\begin{array}{l}0.88 \\
(0.04)\end{array}$ & $\begin{array}{l}64.60 \\
(2.99)\end{array}$ & $\begin{array}{l}1.10 \\
(0.40)\end{array}$ & 0.33 & $\begin{array}{l}26.34 \\
(3.74)\end{array}$ & $\begin{array}{l}25.97 \\
(4.09)\end{array}$ & $\begin{array}{l}0.15 \\
(0.03)\end{array}$ & 0.90 \\
\hline $\begin{array}{l}\text { PCL, } \\
\text { timolol }\end{array}$ & $\begin{array}{l}7.60 \\
(0.32)\end{array}$ & $\begin{array}{l}87.29 \\
(0.46)\end{array}$ & $\begin{array}{l}0.02 \\
(6.51)\end{array}$ & 0.55 & & & & \\
\hline $\begin{array}{l}25 / 75 \\
\mathrm{Lu} / \mathrm{PCL}, \\
\text { timolol }\end{array}$ & $\begin{array}{l}6.99 \\
(0.19)\end{array}$ & $\begin{array}{l}98.55 \\
(0.27)\end{array}$ & $\begin{array}{l}0.01 \\
(8.66)\end{array}$ & 0.40 & & & & \\
\hline $\begin{array}{l}\text { PCL, } \\
\text { acetazo- } \\
\text { lamide }\end{array}$ & $\begin{array}{l}1.24 \\
(0.28)\end{array}$ & $\begin{array}{l}35.14 \\
(1.43)\end{array}$ & $\begin{array}{l}4.11 \\
(0.05)\end{array}$ & 0.92 & $\begin{array}{l}0.00 \\
(4.76)\end{array}$ & $\begin{array}{l}17.09 \\
(4.88)\end{array}$ & $\begin{array}{l}0.24 \\
(0.06)\end{array}$ & 0.82 \\
\hline $\begin{array}{l}25 / 75 \\
\mathrm{Lu} / \mathrm{PCL}, \\
\text { acetazo- } \\
\text { lamide }\end{array}$ & $\begin{array}{l}1.55 \\
(0.60)\end{array}$ & $\begin{array}{l}40.59 \\
(0.62)\end{array}$ & $\begin{array}{l}0.37 \\
(1.48)\end{array}$ & 0.96 & $\begin{array}{l}1.16 \\
(1.66)\end{array}$ & $\begin{array}{l}36.60 \\
(1.92)\end{array}$ & $\begin{array}{l}0.03 \\
(0.01)\end{array}$ & 0.98 \\
\hline $\begin{array}{l}50 / 50 \\
\mathrm{Lu} / \mathrm{PCL}, \\
\text { acetazo- } \\
\text { lamide }\end{array}$ & $\begin{array}{l}1.16 \\
(0.20)\end{array}$ & $\begin{array}{l}30.50 \\
(1.16)\end{array}$ & $\begin{array}{l}0.91 \\
(0.46)\end{array}$ & 0.54 & $\begin{array}{l}10.99 \\
(1.06)\end{array}$ & $\begin{array}{l}14.49 \\
(1.18)\end{array}$ & $\begin{array}{l}0.12 \\
(0.02)\end{array}$ & 0.96 \\
\hline $\begin{array}{l}25 / 75 \\
\mathrm{Lu} / \mathrm{PCL}, \\
\text { acetazo- } \\
\text { lamide }\end{array}$ & $\begin{array}{l}12.67 \\
(0.35)\end{array}$ & $\begin{array}{l}98.08 \\
(0.24)\end{array}$ & $\begin{array}{l}0.05 \\
(0.59)\end{array}$ & 0.99 & & & & \\
\hline
\end{tabular}

Table 4: Drug loading and model parameters determined by non-linear regression 
the elution medium. For the same type of fibers, higher percentages of timolol maleate were released in comparison with acetazolamide (for example, in the case of PCL fibers, $\alpha=45.96$ (2.92) for timolol and $\alpha=35.14$ (1.43) for acetazolamide). This can be explained by the combined effect of lower polymer solubility and higher water solubility of timolol maleate in contrast with acetazolamide that has higher polymer solubility and lower water solubility. The compatibility between drug and polymer is indeed important as it ensures sustained release during drug diffusion from the polymer [26], when the drug is completely encapsulated and dissolved in the fiber.

Fiber composition influenced the release kinetics as drug was released in a more sustained manner from PCL fibers $(\alpha=45.96$ (2.92) and $\mathrm{k}=11.51$ (3.23) for timolol) than from bicomponent fibers regardless of the drug type $(\alpha=50.41$ (2.95) and $\mathrm{k}=12.58$ (2.72) for $25 / 75 \mathrm{Lu} / \mathrm{PCL}$ with timolol, while $\alpha=64.60$ (2.99) and $\mathrm{k}=25.97$ (4.09) for 50/70 Lu/PCL with timolol). Certainly, as erosion was very fast (see section 3.3), the drug was released faster from bicomponent fibers than from the hydrophobic PCL fibers that released the drug at the pace dictated by water uptake.

It was observed that a steady state was attained (after approximately 10 days for bicomponent fibers and after 20 days for PCL fibers) without total release of loaded drug (cumulative release percentages significantly smaller than $100 \%$ ). There is a fraction of the drug that is desorbed from the fiber and then diffuses out through the water filled pores, while another portion of the drug encapsulated probably in crystalline areas (and inaccessible to water) can only be released by polymer degradation (which is insignificant during the time scale of release experiment) [31, 42]. This was not the case for the high drug loading fibers where release was almost complete in the time frame of the experiment. At high loadings, when a significant amount of drug was in crystalline form, only a small portion of drug was trapped (approximately $10 \%$ in the case of PCL, see Fig. 10(a)). As drug was in crystalline state (with crystal dimensions between 1 to $6 \mu \mathrm{m}$ ), additional regions of macroporosity were created after drug dissolution besides those created by water uptake and polymer erosion, increasing surface area and enhancing drug release. Thus, the state of the drug in the fiber has an important part in further controlling release kinetics.

The release kinetics and regression analysis results implied a three stage release mechanism, with different stages depending on fiber composition: the first stage was drug dissolution (mainly because of crystalline drug that is not totally encapsulated in the fibers), the second was drug desorption and 
subsequent diffusion through water-filled pores [43] (created either due to Lu leaching or water uptake in the amorphous regions of PCL), while the last stage was controlled by polymer degradation.

\section{Conclusions}

Fibers were obtained by electrospinning of two semi-crystalline (co)polymers, PCL and Lu, and were loaded with two drugs, acetazolamide and timolol maleate, in concentrations below and above the drug solubility limit in polymer. The PCL fibers were semi-crystalline and hydrophobic, while the bicomponent fibers were semi-crystalline and hydrophilic. Thus, the bicomponent fibers showed high water uptake and extensive erosion during the first day, whereas PCL fibers swelled gradually, without any significant erosion during the time frame of the release experiment. Morphological examination showed that fibers with high drug loadings (above solubility limit) had drug crystals inside and outside the fibers, while fibers with low drug content (below solubility limit) had drug encapsulated in amorphous form. These results were further supported by DSC analysis, where thermograms of low drug loading fibers didn't show the peak corresponding to drug melting.

The high loadings fibers showed higher extent of burst and shorter periods of release (almost $90 \%$ of drug released after 2 days) than low drug content fibers (around $50 \%$ of drug released after 52 days), suggesting that loading and drug encapsulation in either crystalline or amorphous form are interelated and control the release rate, especially in the burst stage. Thus, in long term release applications where high amounts of loaded drug are desirable, a compromise must be found in order to balance the loading and release rate that seem to vary in opposite directions according to the present study.

Total release was not attained at low loadings, suggesting that the last stage of the release kinetics was polymer degradation limited. Moreover, it was observed that timolol maleate was released faster than acetazolamide in the same type of fibers and similar loadings, indicating that drug solubility in polymer influenced the partition of drug between polymer and elution medium. This could offer a mean to control the total percentage of released drug by choosing the best pair of polymer and drug, although some applications require very specific material properties that may not match in terms of compatibility the drugs used in the treatment of the targeted diseases. Finally, the modelling of release data implied a three stage release mecha- 
nism: a dissolution stage (mainly produced by crystalline drug that was not properly encapsulated), a drug desorption coupled to diffusion stage, followed by polymer degradation control stage. The fiber composition also controled drug release, since release was slower from PCL fibers than from bicomponent fibers regardless of the drug type. By choosing the polymers making up the bicomponent fibers and their ratio, the magnitude of the dissolution or diffusion stage can be controlled, attaining the targeted short or long term release application, respectively.

\section{Acknowledgements}

FCT (Fundação para a Ciência e a Tecnologia) financial support is acknowledged by Mădălina V. Natu (SFRH/BD/30198/2006).

\section{References}

[1] M. T. Hunley, T. E. Long, Electrospinning functional nanoscale fibers: a perspective for the future, Polym Int 57 (2008) 385-389

[2] Z.-M. Huang, Y.-Z. Zhang, M. Kotaki, S. Ramakrishna, A review on polymer nanofibers by electrospinning and their applications in nanocomposites, Composites Science and Technology 63 (2003) 22232253

[3] S. Agarwal, J. H. Wendorff, A. Greiner, Use of electrospinning technique for biomedical applications, Polymer 49 (2008) 5603-5621

[4] M J McClure, S A Sell, C E Ayres, D G Simpson, G L Bowlin (2009) Electrospinning-aligned and random polydioxanone-polycaprolactonesilk fibroin-blended scaffolds: geometry for a vascular matrix. Biomed Mater, doi:10.1088/1748-6041/4/5/055010

[5] K M. Sawicka, P Gouma (2006) Electrospun composite nanofibers for functional applications. Journal of Nanoparticle Research, doi:10.1007/s11051-005-9026-9

[6] C L. Casper, W Yang, M C. Farach-Carson, J F. Rabolt (2007) Coating Electrospun Collagen and Gelatin Fibers with Perlecan Domain I for Increased Growth Factor Binding. Biomacromolecules, doi:10.1021/bm061003s 
[7] J A Lee, K C Krogman, M Ma, R M Hill, P T Hammond, G C Rutledge (2009) Highly Reactive Multilayer-Assembled TiO2 Coating on Electrospun Polymer Nanofibers. Adv Mater, doi:10.1002/adma.200802458

[8] Z Ma, M. Kotaki, S. Ramakrishna (2006) Surface modied nonwoven polysulphone (PSU) ber mesh by electrospinning: A novel afnity membrane. Journal of Membrane Science, doi:10.1016/j.memsci.2005.07.038

[9] S J Lee, J J Yoo, G J. Lim, A Atala, J Stitzel (2007) In vitro evaluation of electrospun nanofiber scaffolds for vascular graft application. J Biomed Mater Res A, doi:10.1002/jbm.a.31287

[10] J Zeng, A Aigner, F Czubayko, T Kissel, J H. Wendorff, A Greiner (2005) Poly(vinyl alcohol) Nanofibers by Electrospinning as a Protein Delivery System and the Retardation of Enzyme Release by Additional Polymer Coatings. Biomacromolecules, doi:10.1021/bm0492576

[11] C L. Casper, N Yamaguchi, K L. Kiick, J F. Rabolt (2005) Functionalizing Electrospun Fibers with Biologically Relevant Macromolecules. Biomacromolecules, doi:10.1021/bm050007e

[12] M. Bogntizki, T. Frese, M. Steinhart, A. Greiner, J. H. Wendorff (2001) Preparation of Fibers With Nanoscaled Morphologies: Electrospinning of Polymer Blends. Polym Eng Sci, doi:10.1002/pen.10799

[13] M. Wei, B. Kang, C. Sung, J. Mead (2006) Core-Sheath Structure in Electrospun Nanofibers from Polymer Blends. Macromol Mater Eng, doi:10.1002/mame.200600284

[14] V Kalra, P A. Kakad, S Mendez, T Ivannikov, M Kamperman, Y L Joo (2006) Self-Assembled Structures in Electrospun Poly(styreneblock-isoprene) Fibers. Macromolecules, doi:10.1021/ma052643a

[15] C.M. Vaz, S. van Tuijl, C.V.C. Bouten, F.P.T. Baaijens (2005) Design of scaffolds for blood vessel tissue engineering using a multi-layering electrospinning technique. Acta Biomaterialia, doi:10.1016/j.actbio.2005.06.006

[16] Q P Pham, U Sharma, A G Mikos (2006) Electrospun Poly(Ecaprolactone) Microfiber and Multilayer Nanofiber/Microfiber Scaffolds: 
Characterization of Scaffolds and Measurement of Cellular Infiltration. Biomacromolecules, doi:10.1021/bm060680j

[17] T Okuda, K Tominaga, S Kidoaki (2009) Time-programmed dual release formulation by multilayered drug-loaded nanober meshes. Journal of Controlled Release, doi:10.1016/j.jconrel.2009.12.029

[18] W Cui, X Li, X Zhu, G Yu, S Zhou, J Weng (2006) Investigation of Drug Release and Matrix Degradation of Electrospun Poly(DLlactide) Fibers with Paracetanol Inoculation. Biomacromolecules, doi:10.1021/bm060057z

[19] G Buschle-Diller, J Cooper, Z Xie, Y Wu, J Waldrup, X Ren (2007) Release of antibiotics from electrospun bicomponent fibers. Cellulose, doi: $10.1007 / \mathrm{s} 10570-007-9183-3$

[20] El-Refaie Kenawy , Gary L. Bowlin , Kevin Mansfield , John Layman , David G. Simpson, Elliot H. Sanders, Gary E. Wnek, Release of tetracycline hydrochloride from electrospun poly(ethylene-co-vinylacetate), poly(lactic acid), and a blend, Journal of Controlled Release 81 (2002) $57-64$

[21] Z Xie, G Buschle-Diller (2009) Electrospun Poly(D,L-lactide) Fibers for Drug Delivery: The Influence of Cosolvent and the Mechanism of Drug Release. Journal of Applied Polymer Science, doi: 10.1002/app.31026

[22] M Zamani, M Morshed, J Varshosaz, M Jannesari (2010) Controlled release of metronidazole benzoate from poly ( $\epsilon$-caprolactone) electrospun nanobers for periodontal diseases. European Journal of Pharmaceutics and Biopharmaceutics, doi:10.1016/j.ejpb.2010.02.002

[23] J Xie, C-H Wang (2006) Electrospun Micro- and Nanofibers for Sustained Delivery of Paclitaxel to Treat C6 Glioma in Vitro. Pharmaceutical Research, doi: 10.1007/s11095-006-9036-z

[24] P Taepaiboon, U Rungsardthong , P Supaphol (2006) Drug-loaded electrospun mats of poly(vinyl alcohol) fibres and their release characteristics of four model drugs. Nanotechnology, doi:10.1088/0957$4484 / 17 / 9 / 041$ 
[25] S Y Chew, J Wen, E K F Yim, K W Leong (2005) Sustained Release of Proteins from Electrospun Biodegradable Fibers. Biomacromolecules, doi: 10.1021/bm0501149

[26] J Zeng, L Yang, Q Liang, X Zhang, H Guan, X Xu, X Chen, X Jin (2005) Influence of the drug compatibility with polymer solution on the release kinetics of electrospun fiber formulation. Journal of Controlled Release, doi:10.1016/j.jconrel.2005.02.024

[27] R.A. Thakur, C.A. Florek, J. Kohn, B.B. Michniak, Electrospun nanofibrous polymeric scaffold with targeted drug release profiles for potential application as wound dressing, International Journal of Pharmaceutics 364 (2008) 87-93

[28] Deng-Guang Yu, Xia-Xia Shen, Chris Branford-White, Kenneth White, Li-Min Zhu and S W Annie Bligh, Oral fast-dissolving drug delivery membranes prepared from electrospun polyvinylpyrrolidone ultrafine fibers, Nanotechnology 20 (2009), 1-9.

[29] M.V. Natu, M.H. Gil, H.C. de Sousa, Supercritical solvent impregnation of $\operatorname{poly}(\varepsilon$-caprolactone)/poly(oxyethylene-b-oxypropyleneb-oxyethylene) and poly(Ecaprolactone)/poly(ethylene-vinyl acetate) blends for controlled release applications, J. Sup. Fluids 47 (2008) 93102 .

[30] N.A. Peppas, L. Brannon-Peppas, Water Diffusion and Sorption in Amorphous Macromolecular Systems and Foods, J Food Eng 22 (1994) 189-210.

[31] R. Srikar, A. L. Yarin, C. M. Megaridis, A. V. Bazilevsky, E. Kelley, Desorption-Limited Mechanism of Release from Polymer Nanofibers, Langmuir 2008, 24, 965-974

[32] ImageJ, Image processing and analysis in Java, http://rsbweb.nih. gov/ij/, Accesed March 9, 2010.

[33] H. Tsuji, Y. Ikada, Blends of Aliphatic Polyesters. II. Hydrolysis of Solution-Cast Blends from Poly( L-lactide ) and Poly( $\varepsilon$-caprolactone) in Phosphate-Buffered Solution, J Appl Polym Sci 67 (1998) 405-415. 
[34] ATHAS data bank, http://athas .prz.edu.pl/Default. aspx?op=db, Accesed March 9, 2010.

[35] http://www.openoffice.org/, Accesed March 9, 2010.

[36] http://www.sigmaplot.com/products/sigmaplot/ sigmaplot-details.php, Accesed March 9, 2010.

[37] Drug card for timolol (DB00373), DrugBank database, http://www . drugbank.ca/drugs/DB00373, Accesed March 9, 2010.

[38] Drug card for acetazolamide (DB00819), DrugBank database, http: //www.drugbank.ca/drugs/DB00819, Accesed March 9, 2010.

[39] M. Kang, R. Jung, H.-S. Kim, H.-J. Jin, Preparation of superhydrophobic polystyrene membranes by electrospinning, Colloids and Surfaces A: Physicochem. Eng. Aspects 313-314 (2008) 411-414.

[40] M. Wei, B. Kang, C. Sung, J. Mead, Core-Sheath Structure in Electrospun Nanofibers from Polymer Blends, Macromol. Mater. Eng. 291 (2006) 1307-1314.

[41] A. Hglund, M. Hakkarainen, A.-C. Albertsson, Degradation Profile of Poly(E-caprolactone)-the Influence of Macroscopic and Macromolecular Biomaterial Design, J. Macromolecular Sci. Part A, 44 (2007) 10411046.

[42] A.R. Tzafriri, Mathematical modeling of diffusion-mediated release from bulk degrading matrices, J Con Rel 63 (2000) 69-79.

[43] M. Miyajima, A. Koshika, J. Okada, M. Ikeda, K. Nishimura, Effect of polymer crystallinity on papaverine release from poly(L-lactic acid) matrix, Journal of Controlled Release 49 (1997) 207-215 